\title{
Study on the Construction of Translation Flipped Classroom Teaching Model Based on Micro Class
}

\author{
Wu Wenmin* \\ Harbin University of Commerce Harbin, Heilongjiang Province, China. \\ * Corresponding author. Tel.: 17758889837; email: mengyaodiana@126.com \\ Manuscript submitted May 13, 2017; accepted July 16, 2017. \\ doi: 10.17706/ijeeee.2018.8.2.91-96
}

\begin{abstract}
Through analyzing the basic ideas and methods adopted by micro classes and flipped classroom teaching mode in contemporary China, combing relative theoretic knowledge, this paper enriches translation micro class resources and teaching research on flipped classroom; meanwhile, the writer discusses how to build a new translation flipped classroom teaching mode based on micro classes, exploring superior design standards and evaluation standards for micro classes as well as the evaluation system of flipped classroom teaching mode.
\end{abstract}

Key words: Flipped classroom, micro class, the construction of translation teaching mode.

\section{Introduction}

As the contextualized online video course resources supporting multiple learning ways, "micro class" takes the micro teaching video as the main carrier, designed and developed for a key point in some discipline knowledge (e.g. focus, difficulty and doubt, the examination site, etc.) or for certain teaching links (such as learning activities, theme, experiment, tasks, etc.) [1]. The affiliated school of American Iowa University put forward Minicourse in 1960, ever since then, micro classes has caused wide public concern abroad. Combing foreign studies, the writer found the following problems: 1) The structure and organization of micro classes are not in the same accord; 2) Micro class is used in a relatively concentrated way, mainly for students' learning or teachers' training; 3) The depth is not enough, and the makers are thoughtless in resources expansion. Domestic research on micro class starts late, vast in fields, unbalanced in development, mainly on the basic theory and design application, less attention paid to related technologies and evaluation system. At present there is no consistent theoretical framework and mature mode of application in China. Micro class is not intricately made, ignoring the integration with classroom, etc. which is also a problem urgently to be solved in the study.

"Flipped classrooms" originated from the American forest park high school along Colorado Rocky mountain. Foreign research mainly focused on its application in teaching practice, comparative research with traditional teaching mode and exploration on the application effect of combining flipped classroom with other teaching methods or technologies, etc. It is the "with video reshape education" released by Salman Khan, the originator of Khan College, in TED in 2011 that aroused domestic education researchers' attention [2]. Domestic research has focused on: 1) The concept introduction and wonderful cases recommendation; 2) Comparative research on traditional teaching mode; 3) The challenges and bottlenecks of flipped classroom in domestic localization practice; 4)The application research on flipped classroom. The 
research perspectives of flipped classroom seem comprehensive, but after the analysis on a micro level, it's easy to find that the basic research on flipped classroom stays on the introduction of its origin, evolution and status, repetitive in research content; hidebound patterns are easily seen in the applied research and teaching design, with generally the same view; no breakthrough in the flipped classroom technology research, which will be the future research direction.

The in-depth application of information technology in the education and teaching field presents great challenges for the traditional classroom. To meet the challenges, it has to be reformed, while flipped classroom turns to be an effective way to change the traditional classroom [3]. In the era of "Internet +", on the basis of micro class resources, the flipped classroom teaching mode evolves into a blended learning model, with self-study before class and strengthened learning in class as the main form, realizing the student-centered personal learning mode, meeting with the new direction of information teaching reform [4].

MS Excel course of Marriott School of Management, Brigham Young University and the control system course of Mechanical Engineering department, Seattle university has achieved obvious accomplishments after the flipped classroom practice [5]; some domestic scholars also began to carry out the experimental study combining courses, through questionnaire, interview, test results contrast, etc. to demonstrate the effectiveness of specific application mode [6]. However, the existing research ignores the design and research of knowledge transfer before, and to flip the classroom, the key is the design and cohesion before class, in class and after class activities, in order to achieve the integration of activities before class, in class and after class.

\section{Design and Manufacture of Micro Class}

As an important part of the flipped classroom, micro class determines the effect of knowledge transfer before class, influences the design of teaching activities in class, which in turn affects the final teaching result. Micro class used to flip the classroom should not be a complete class, but a collection of one segment or several teaching activities in the service of a class, and exhibited through the network teaching platform. Micro class contains the micro video of teacher's explanation and demonstration, complementary with such learning resources as the courseware, case, and source materials, etc.; meanwhile it includes micro online exercises, supplemented by such learning feedback of self-study activities as online FAQ, online testing, online survey, etc.

Although flipped classroom is a new type of teaching mode, it is still inevitable to make students feel bored. So considering the design of micro classes used to flip the classroom, its scene can not be too single. Appropriate research tasks should be increased timely to realize the interaction lack in traditional classroom.

\section{Teaching Structure and Design of English-Chinese Translation Flipped Classroom}

Translation theory course is relatively dull. Students may encounter various difficulties while studying by themselves. Therefore it is recommended that teacher's explanation on translation theoretical knowledge should be carried out in the classroom; while the translation practice takes longer, and it is also difficult to carry out individual counseling in class [7]. So in flipped classroom teaching mode the more exercises of translation practice are to be carried out by students themselves after class. Students are requested to complete the specified translation exercises before class; in-class time is used by the teacher for evaluation; translation theoretical knowledge and translating abilities will be further deepened and consolidated through online discussion after class. In this way, certain attention is doomed to be paid to theoretical knowledge learning and instruction, at the same time, through a lot of practice micro classes, aiming at 
training students' theoretical and practical knowledge, make the students capable of undertaking translation or interpretation work independently, and can be flexible.

Flipped class is the flip of teaching structure [8]. Through a series of research on the concepts and characteristics of micro class and flipped classroom, as well as the analysis of the characteristics of English teachers in domestic colleges and universities, college students' learning characteristics, the current translation teaching mode, and teaching environment, the writer intends to build up the flipped classroom teaching mode based on micro classes in English-Chinese translation course. Based on a careful study of related researches at home and abroad, the flipping process of classroom teaching structure can also be shown in figure 1 in details. This mode realizes the knowledge transfer, knowledge construction, knowledge internalization, knowledge consolidation and knowledge expansion via the pr-designed task pass assignments before class, typical tasks in class and development tasks after class. Specific process is shown in Fig. 1:

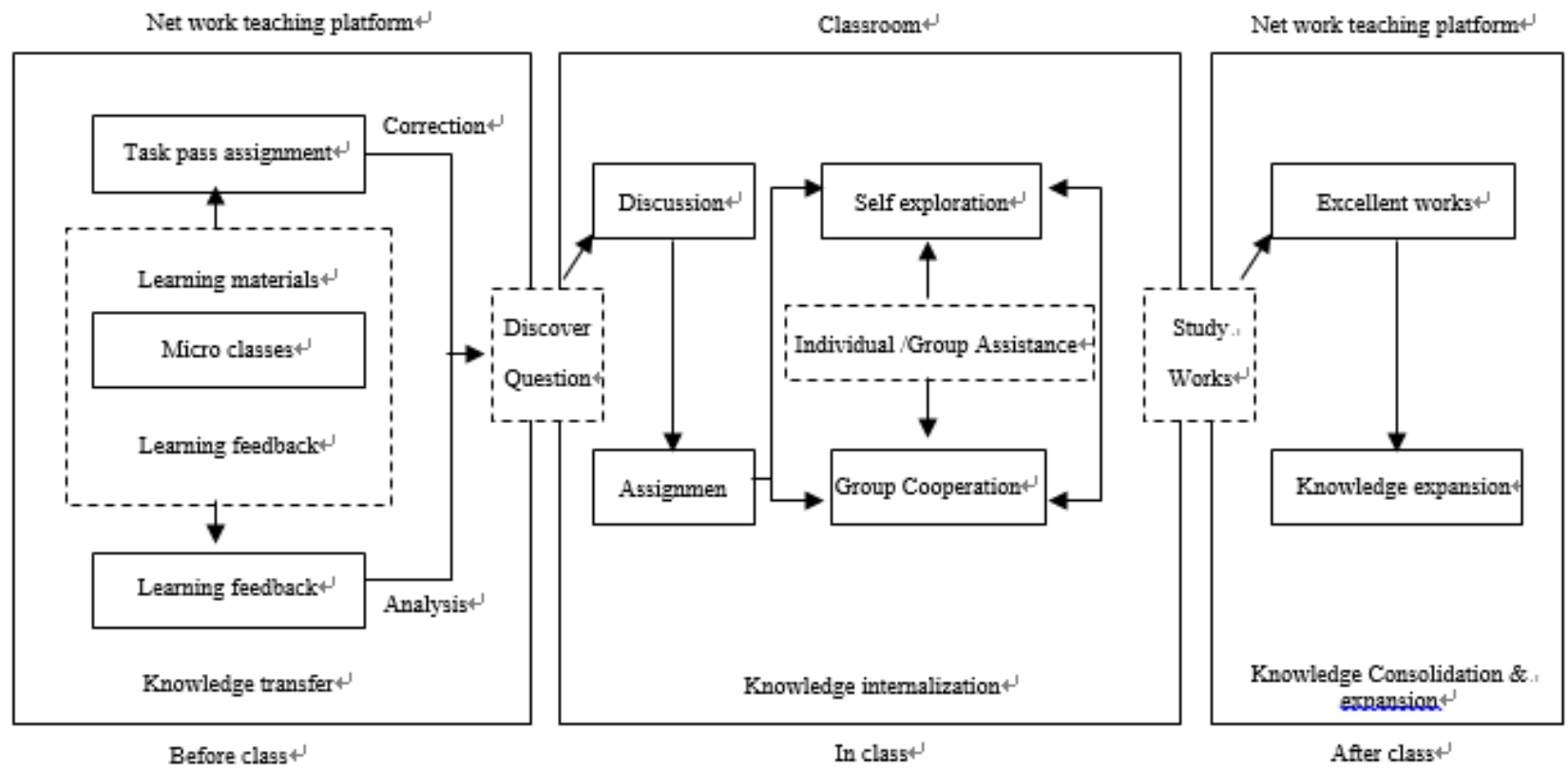

Fig. 1. Flipped classroom teaching mode.

\section{Translation Flipped Classroom Teaching Mode Based on Micro Class}

Tracking the teaching and learning effects of English-Chinese translation course, and building up the flipped classroom teaching and learning mode based on micro class, the general framework can be as follows:

\subsection{Open Teaching Mode of "Inside Class + Outside Class"}

The writer chose the English-Chinese translation course to carry out the open teaching experiment through regular classroom teaching + self learning online before and after class. Modern educational technology and means are fully applied in the teaching process to realize the organic integration of modern multimedia teaching resources and traditional classical teaching resources [9]. Develop and establish a translation resource library, including professional learning website, online courses, text, images, animation, video, etc. Relying on such rich network learning resources, the writer carried out the open teaching mode as student centered + teacher leading, which organically integrated the traditional classroom teaching and the extracurricular real-time "network second classroom" (see Fig. 2). 


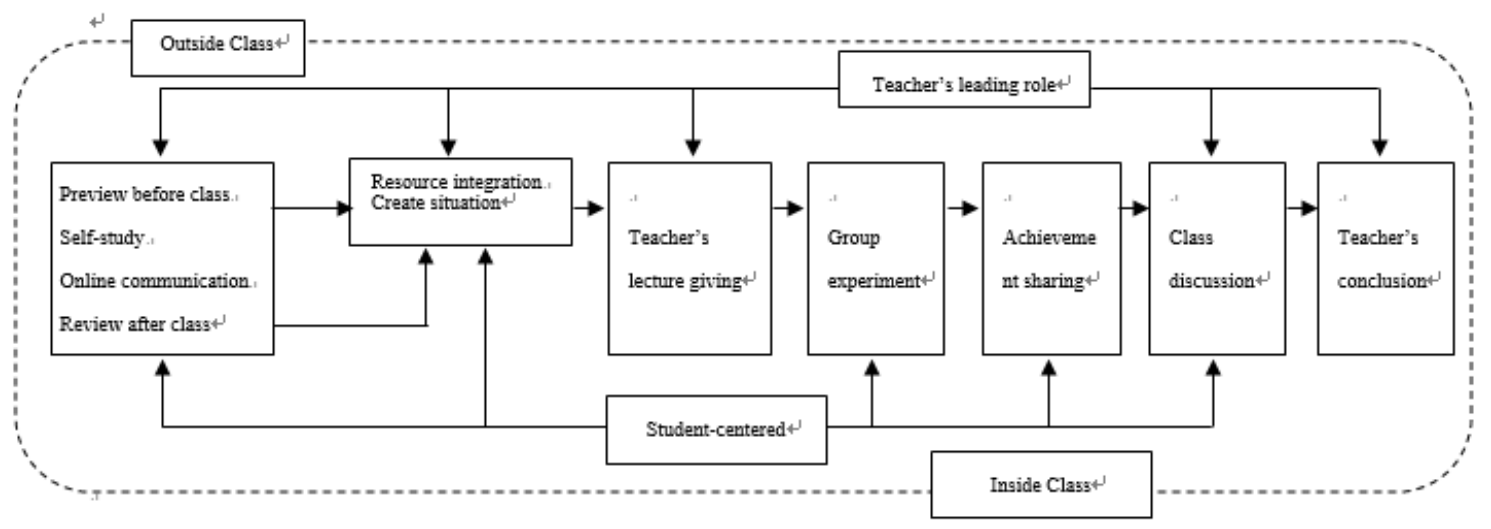

Fig. 2. The open teaching mode of "inside+outside class".

\subsection{Collaborative Learning Mode Based on Problem Solving}

Collaborative learning mode based on problem solving emphasizes putting learning in the complex and meaningful problem settings. Students learn the implicit knowledge of science hidden at the back of problems by the learners' cooperation to solve the problems, thus develop their problem solving abilities, improve their ability of autonomous learning and lifelong learning, consequently become effective collaborators. This mode promotes the development of students' various senior cognitive capabilities, improves students' ability to deal with problems, solve problems and generate new knowledge, meanwhile cultivates their ability of independent learning and team work. Specific operation is shown in Fig. 3:

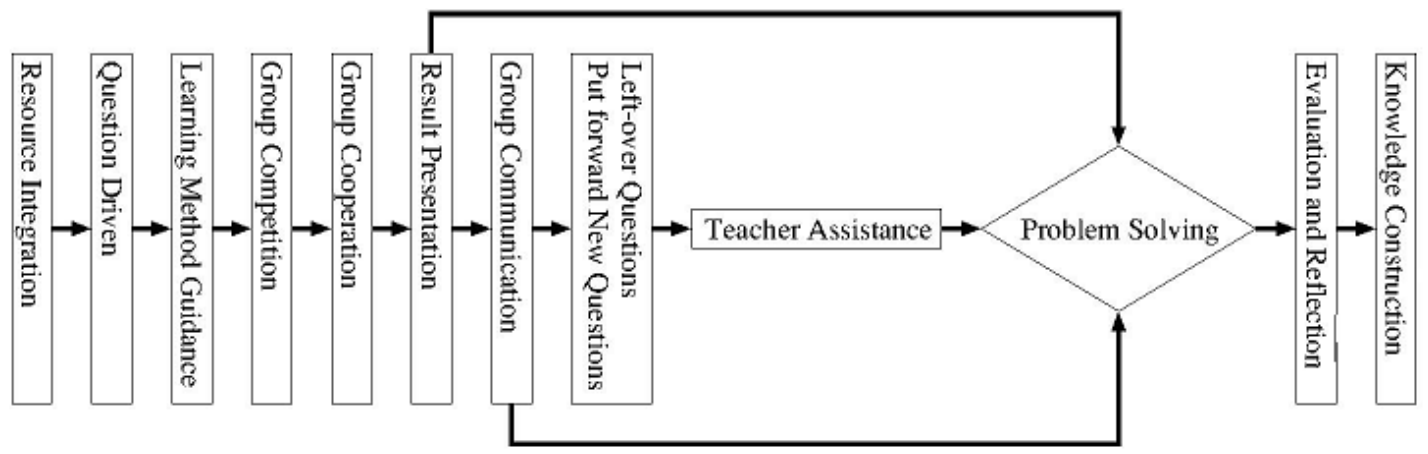

Fig. 3. Collaborative learning mode based on problem solving.

\begin{tabular}{|l|}
\hline Platform Construction \\
Learning Resources Integration \\
\hline Course Notice \\
\hline Searning Material Release \\
\hline Online Discussion \\
\hline Hand in Homework and Evaluate online \\
\hline Online Exam \\
\hline
\end{tabular}

Fig. 4. Learning mode of teacher leading and students' self exploration. 


\subsection{Teacher Leading and Self-exploring Learning Mode}

This teaching mode concentrates on students' self learning merely, which is based on a complete network teaching platform and learning resources. It mainly includes the following several parts (see Fig. 4).

In the learning process of this mode, teachers should organize several face-to-face lectures, such as at the beginning of the semester, before the midterm and final exam, etc., through face-to-face lecture to enhance the emotional communication between teachers and students, consequently strengthen the teachers' leading role in the course.

\section{Conclusion}

Flipped classroom teaching mode based on micro class makes it possible to combine classroom teaching with digital teaching; research and collaborative learning can be carried out through the network platform; the teacher can also control the learning process of students through the control of teaching contents' rendering time [10]. This model will utilize the advantage of network teaching more fully, make up for the inadequacy of traditional classroom teaching, and meet the diverse individual demands of different levels students, improving their learning interest and study initiative.

\section{Acknowledgments}

First of all, I would like to extend my sincere gratitude to the school library, without which I shall not get the conference news timely. High tribute shall be paid to Mr. Hu Kaibao, whose profound knowledge of English triggers my love for this beautiful language and whose earnest attitude tells me how to carry out English research. Special thanks should go to my colleagues who have put considerable time and effort into their comments on the draft. Finally, I am indebted to my husband for his continuous support and encouragement.

This paper is the Phased research results of the Subject construction project of Harbin University of Commerce: Study on the cultivation mode of internationalized foreign language talents in Heilongjiang Province under the strategic background of "Silk Road belt".

\section{References}

[1] Guan, Z. K. (2011). The Integration of Computer Network and Foreign Language Courses - A Study on College English Teaching Reform. Shanghai: Shanghai Foreign Language Education Press.

[2] Zhang, Y. G., \& Zhang, Y. J. (2012). Design of translation course's electronic file based on Mahara platform. Chinese Remote Education, (3).

[3] Lu, H. Y. (2014). The feasibility analysis of the application of flipped classroom in college English teaching. Foreign Language Electrochemical Education, 7, 33-36.

[4] Yong, F. F. (2016). Study on the application of flipped classroom teaching mode based on micro class in the inorganic and organic chemistry practical teaching course. Popular Science Education (Scientific Education).

[5] Daves, N. B. (2013). The Flipped Classroom Strategy: What Is It and How Can It Best Be Used?. Greenwich: Distance Learning.

[6] Yang, J. M. (2013). Study on the application of flipped classroom based on micro video resources in the experimental teaching course - Take the "Modern Education Technology" experiment course as an example. Modern Educational Technology, (10), 36-40.

[7] Wu, W. M. (2017). Study on the application of flipped classroom based on micro-class in college English visual-audio-oral course. Literature and Art Life.

[8] Goodwin, B., \& Miller, K. (2013). Evidence on Flipped Classrooms Is Still Coming In. Educational 
Leadership.

[9] Strayer, J. (2007). The Effects of the Classroom Flip on the Learning Environment: A Comparison of Learning Activity in A Traditional Classroom and Flip Classroom that Used An Intelligent Tutoring System.

[10] (2014). Four Different Blended Learning Model — The Flipped Classroom Model.

Wu Wenmin is associate professor, a postgraduate from Nankai University, who has been teaching English in Harbin University of Commerce since 2006, mainly giving lectures such as college English, literary translation, international etiquette and cross-cultural communication, theory and practice of Chinese-English translation. 